\title{
AN AIR QUALITY MANAGEMENT SYSTEM FOR CYPRUS
}

\author{
N. MOUSSIOPOULOS ${ }^{1}$ \\ I. DOUROS ${ }^{1, *}$ \\ G. TSEGAS ${ }^{1}$ \\ S. KLEANTHOUS ${ }^{2}$ \\ E. CHOURDAKIS ${ }^{1}$
}

Received: 18/01/10

Accepted: 12/02/10

\author{
${ }^{1}$ Laboratory of Heat Transfer and Environmental \\ Engineering, Aristotle University of Thessaloniki, Greece \\ ${ }^{2}$ Department of Labour Inspection, \\ Ministry of Labour and Social Insurance, Nicosia, Cyprus
}

*to whom all correspondence should be addressed: e-mail: jdouros@aix.meng.auth.gr

\begin{abstract}
The new Air Quality Directive (2008/50/EC) encourages the introduction of modelling as a necessary tool for air quality assessment and management. Towards this aim, a new Air Quality Management System (AQMS) has been developed and installed in the Department of Labour Inspection of the Republic of Cyprus.

The core of the system handles the compilation of an emissions inventory that includes data from all major activity sectors and functions on the basis of a continuous update of the emissions database. Emission data are then fed into an advanced air quality modelling system that simulates concentration fields for all the major air pollutants over the island of Cyprus. The AQMS comprises of two operational modules, providing hourly nowcasting and daily forecasting of the air quality status, implemented as an integrated model system that performs nested grid meteorological and photochemical simulations. Hourly air quality data from nine measuring stations are continuously assimilated into these model calculations. A third operational module provides the capability of an interactive configuration of custom emission scenarios and corresponding model runs covering user-defined domains of interest. The system provides an advanced user interface, which is realised as a web-based application providing access to model results from any computer with an internet connection and a web browser.
\end{abstract}

KEYWORDS: air quality, air quality management, air quality modelling, nowcasting, forecasting, emission scenario.

\section{INTRODUCTION}

The new Air Quality Directive (2008/50/EC) introduces additional requirements for air quality assessment and management. As a result, along with air quality measurements, modelling tools should also be used by authorities and policy makers in order to assess pollutant concentrations in ambient air. It also requires that up-to-date information on concentrations of all regulated pollutants in ambient air should be readily available to the public. Towards this aim, an operational web based system for Air Quality Management developed by the Laboratory of Heat Transfer and Environmental Engineering (LHTEE) has been installed in the Department of Labour Inspection (DLI) of the Ministry of Labour and Social Insurance in the Republic of Cyprus. The system offers a range of features for nowcasting, forecasting and performing scenario calculation for air quality in Cyprus. The main goals of the system lie in providing useful up-to-date information to the public on pollutant concentrations in ambient air, as well as supporting local authorities and decision makers in air quality assessment and management. 


\section{METHODOLOGY}

The core of the system handles the compilation of an emissions inventory that includes data from all major activity sectors and functions on the basis of a continuous update of the emissions database. This part of the software dealing with emissions provides functionality for setting up emission scenarios based both on the application of measures as well as targeted modifications. Emission data are prepared as an emissions grid (see Figure 1) that is subsequently fed into the air quality modelling system (Kleanthous et al., 2009).

The part of the AQMS dealing with the calculation of ambient concentrations has a functional structure similar to that followed by most AQMSs operating on an around-the-clock basis (see Figure 2). The AQMS comprises of two operation modes, nowcasting and forecasting, which are implemented based on an automated scheme that performs nested grid meteorological and photochemical model simulations. The mesoscale meteorological model MEMO and the chemistry-transport model MARS-aero are used for this purpose, both parts of the EZM (European Zooming Model) system (Moussiopoulos, 1995). MEMO (Moussiopoulos et al., 1993) is a three-dimensional, non-hydrostatic, prognostic mesoscale model which simulates mesoscale air motion and inert pollutant dispersion at the local-to-regional scale, over complex terrain, allowing multiple nesting. MARS-aero (Moussiopoulos et al., 1995) is an Eulerian chemistry-transport model for reactive species operating at similar scales. The modular structure of MARS-aero allows any of four chemical reaction mechanisms for the gaseous phase to be used, while the calculation of secondary aerosols, organic and inorganic, can be enabled at will (Arvanitis et al. 2001, Schell et al. 2001). Meteorological data such as wind speed, temperature, TKE, surface roughness, Monin-Obukhov length and friction velocity are required input for the dispersion calculations and are provided by MEMO. Both MEMO and MARS-aero are used in a nested configuration (see Table 1).

Table 1. Description of MEMO and MARS-aero nested grids

\begin{tabular}{|c|c|c|c|c|c|}
\hline & $\begin{array}{c}\text { Depth of } \\
\text { nesting }\end{array}$ & $\begin{array}{c}\text { Number of } \\
\text { nested grids }\end{array}$ & Grid size & Grid resolution & Type of nesting \\
\cline { 1 - 4 } Coarse & 2 & 1 & $60 \times 60$ & $25 \mathrm{~km}^{2}$ & \multirow{2}{*}{ 1-way } \\
\cline { 1 - 4 } Fine & 2 & 5 & $50 \times 50$ & $1 \mathrm{~km}^{2}$ & \\
\hline
\end{tabular}

For the initialisation of MEMO, a number of vertical profiles of the key meteorological variables originating from the Global Forecast System (GFS) are used (URL1). Such profiles are also assimilated into the model calculations on a 3-hour basis. The downloader module of the automated system undertakes the downloading of the GFS data, processes them and stores them in a data pool which is kept updated at all times (see Figure 3). The scheduler selects only the most recent dataset for input to the MEMO model. In case of an emergency, e.g. when no new data are available, older datasets are automatically used. Each of these processes keeps a separate event log and diagnostic files accessible to the operator of the system.

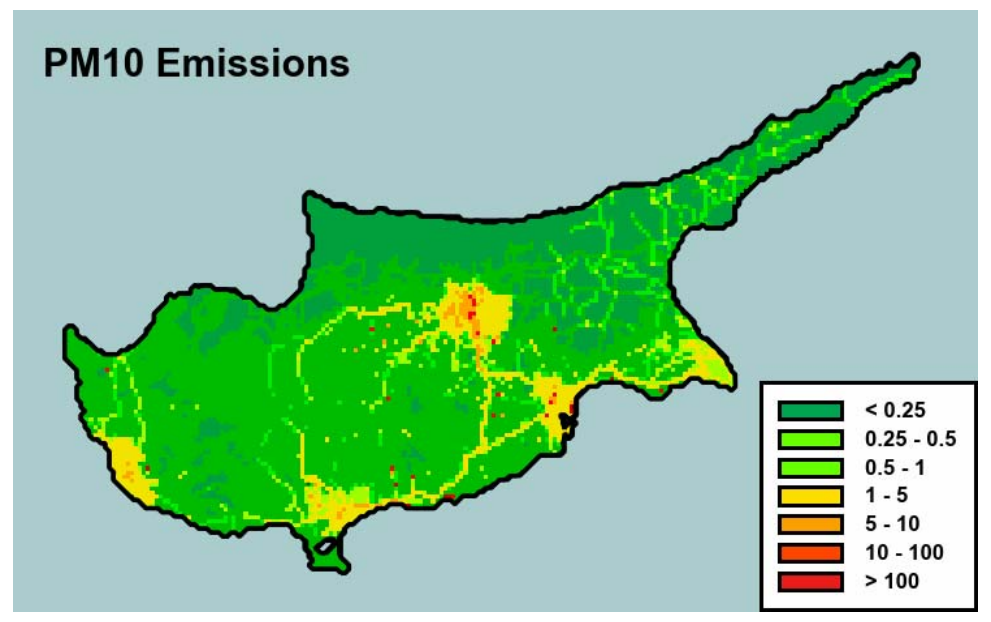

Figure 1. $\mathrm{PM}_{10}$ emissions map for the whole of Cyprus for a typical weekday (in $\mathrm{kg} \mathrm{km}^{-2}$ ) 


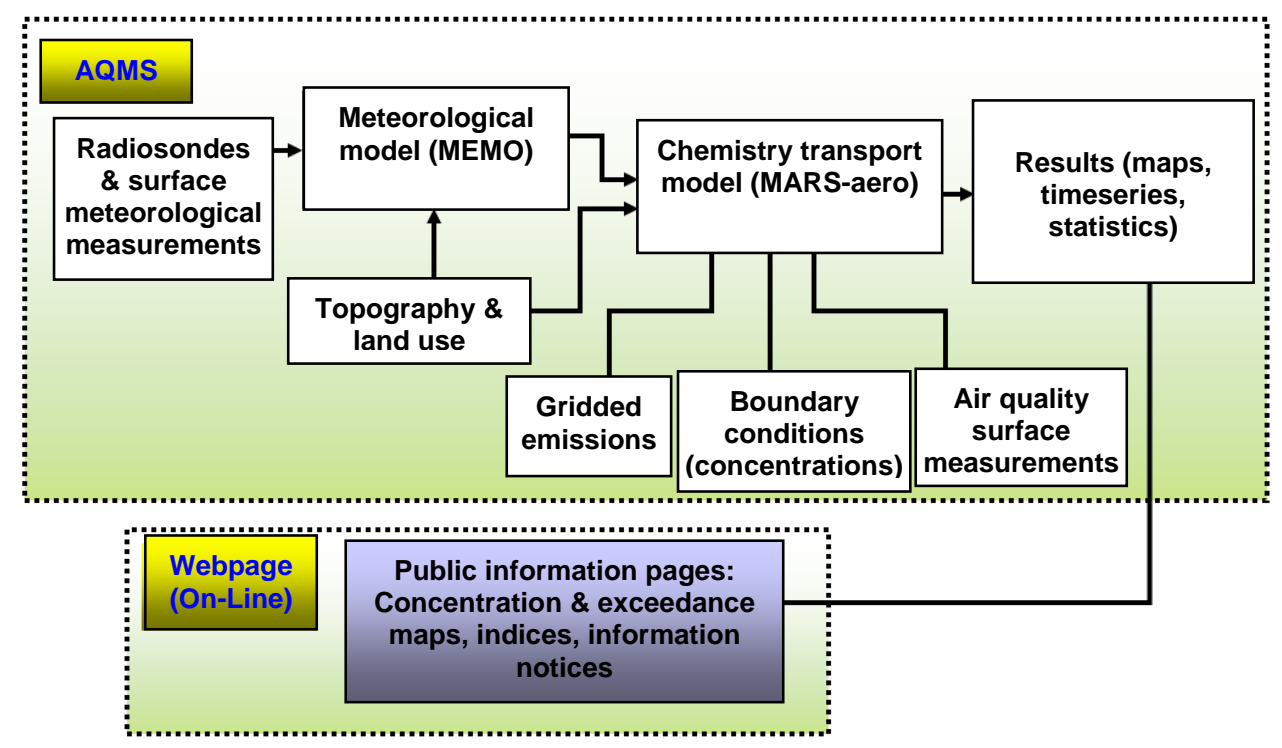

Figure 2. The structure of the Air Quality Management System

The MARS-aero model runs back-to-back with the MEMO model, featuring real time integration of ambient pollutant concentration data that are provided both from valid measurement data, as well as from larger scale models results and are used both as initial and lateral conditions in the model calculations as well as for data assimilation purposes. An upgraded methodology has been developed and incorporated in the system's core for providing increased flexibility in the coupling of the nested domains. Additionally, a dynamic dust concentration component is included in the $\mathrm{PM}_{10}$ and $\mathrm{PM}_{25}$ boundary conditions that are fed in the model core, so as to improve the accuracy of calculated PM concentrations during Saharan dust episodes. These upgrades significantly enhance the operational prognostic skills of the AQMS in the cases of elevated concentration levels that are associated with transboundary transport of air pollutants.

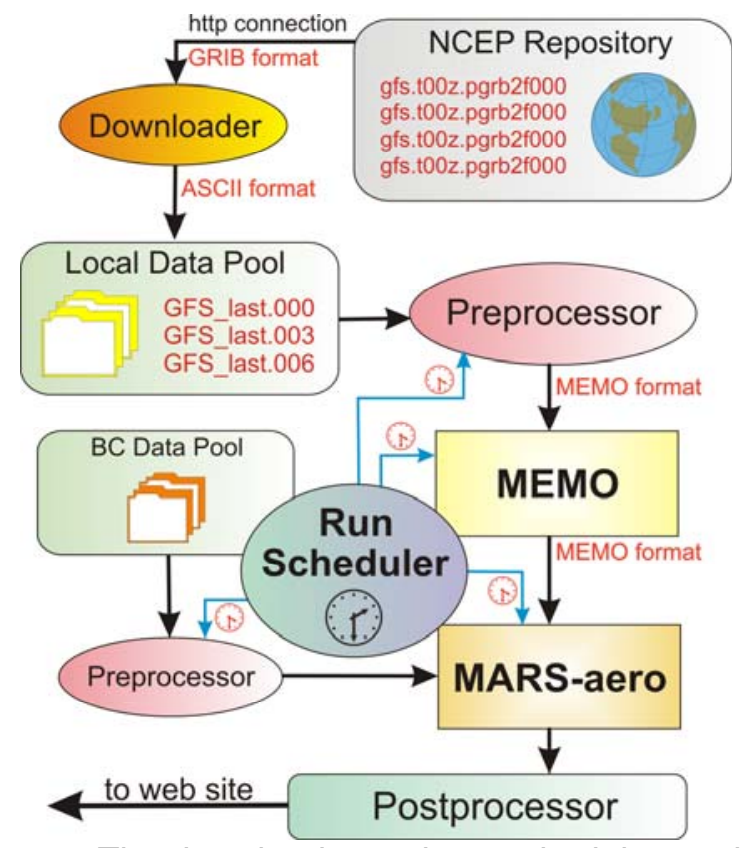

Figure 3. The downloader and run scheduler modules

In nowcasting mode the system computes, on an hourly basis, the pollutant concentration fields in Cyprus and, at higher resolution, in the five largest cities. Model results are automatically processed and a range of maps, timeseries graphs and statistical indices are 
produced for five major pollutants, namely $\mathrm{PM}_{10}, \mathrm{PM}_{2.5}, \mathrm{NO}_{2}, \mathrm{O}_{3}$ and benzene. These results become available to the public via DLl's web page (URL2) and are also accessible in even greater detail to the staff of the department. In forecasting mode 24-hour photochemical model simulations are driven by corresponding prognostic meteorological simulations of GFS, in order to produce daily air quality forecast maps and graphs for the domains of interest and the prescribed pollutants. Daily forecasts become available to the department and the public through a set of web pages accessible through a similar interface.

The system's user interface is realised as a web based application which is accessible from any computer having internet access. Through this interface, the authorized DLI users are provided with numerous possibilities for reviewing both the process and the results of the calculations as well as for configuring the information that becomes available in the public web-page. The informational public pages represent a very important aspect of the system's structure as, in addition to the concentration levels, the public is also informed on the expected health impacts of the forecasted air quality situation, thus allowing them to manage their activities accordingly.

The AQMS can also be operated by DLI to support air quality related assessment and decision making, by allowing interactive configuration of custom emission scenarios and corresponding model runs. This operational module provides the capability to study emission scenarios and assess their effect on air quality in the five major urban areas of Cyprus or over user-defined domains. The meteorology used for assessment calculations is based on a number of representative meteorological situations which are analysed and duly weighted according to the frequency of their occurrence during a full calendar year.

\section{RESULTS}

Through the system's interface the public and the authorized DLI users can view the model results, both for nowcasting and forecasting. In the nowcasting section, hourly meteorological and air quality maps are available to any computer with an internet connection through interactive web pages (see Figures 4 and 5). The public is also informed on the expected health impacts of the forecasted air quality situation by messages that are automatically produced and constitute a statement about the expected exposure to air pollution levels on an hourly basis.

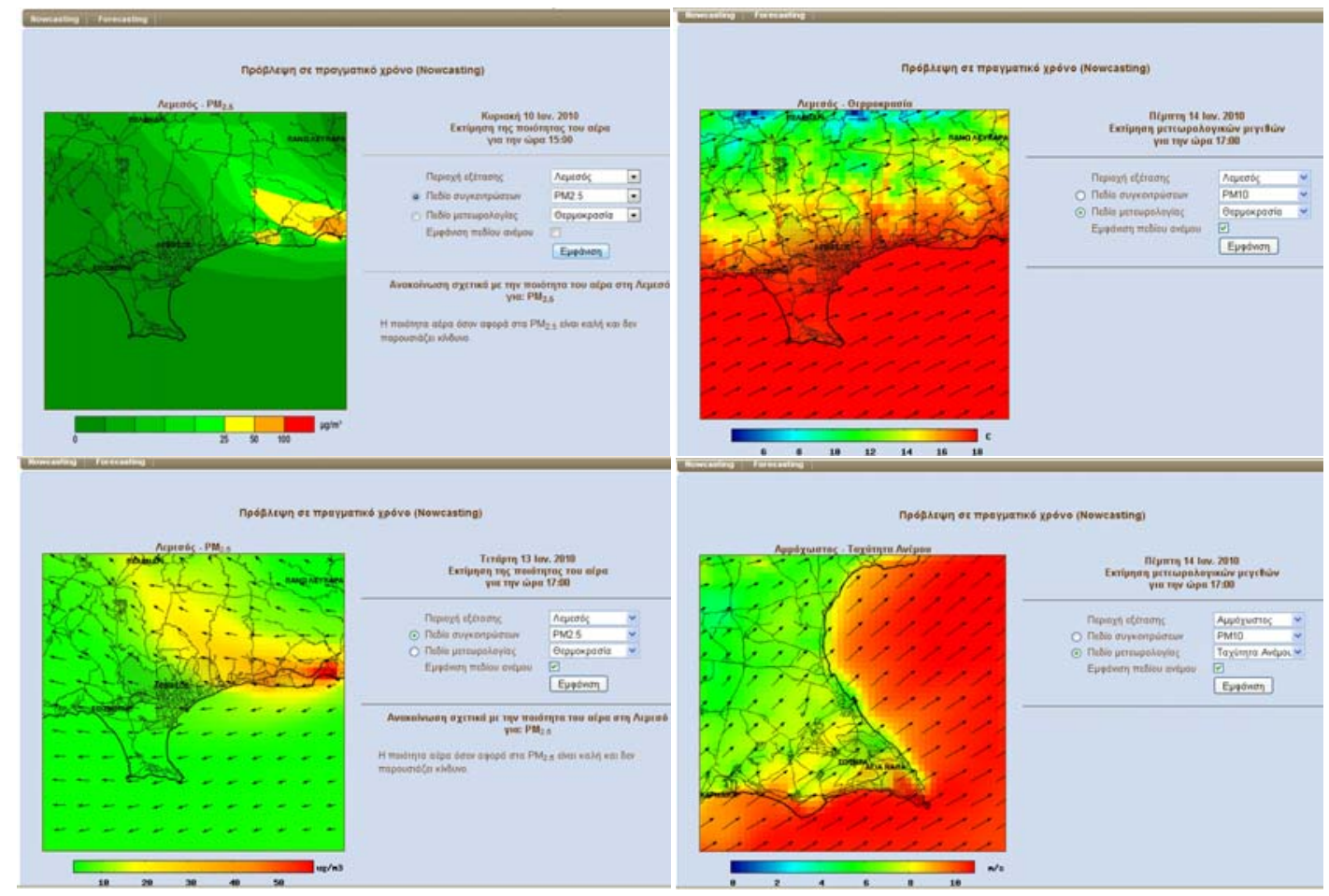

Figure 4. Snapshots of nowcasting for pollutant concentrations (left) and meteorological parameters (right) 


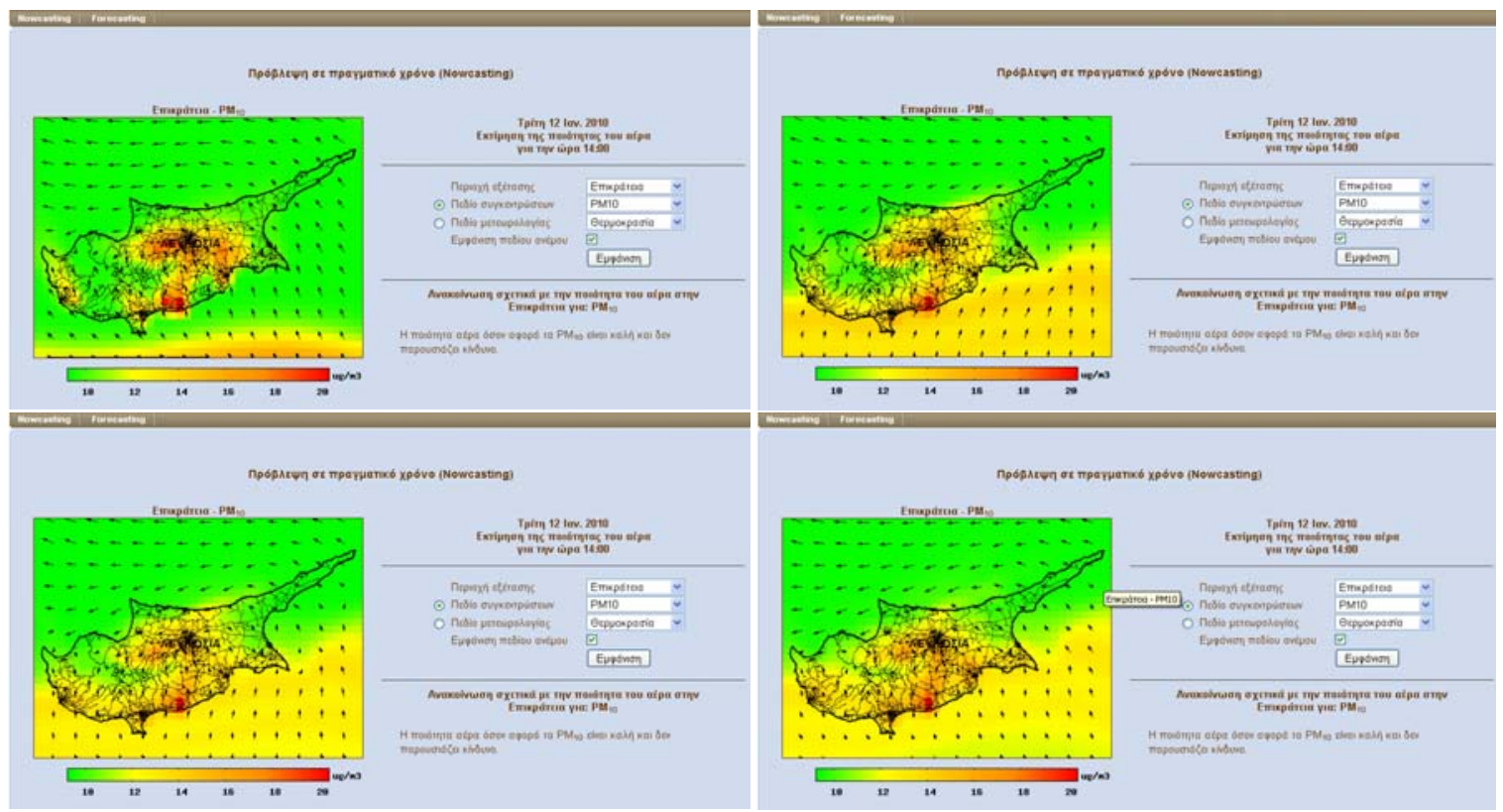

Figure 5. Snapshots of nowcasting results for $\mathrm{PM}_{10}$ during Saharah dust episode

In the forecasting section of the web interface, a wide range of maps, timeseries graphs and statistical indices are made accessible to the public, providing information both on forecast pollutant concentrations as well as on meteorological parameters, such as temperature, relative humidity and wind speed (see Figure 6).

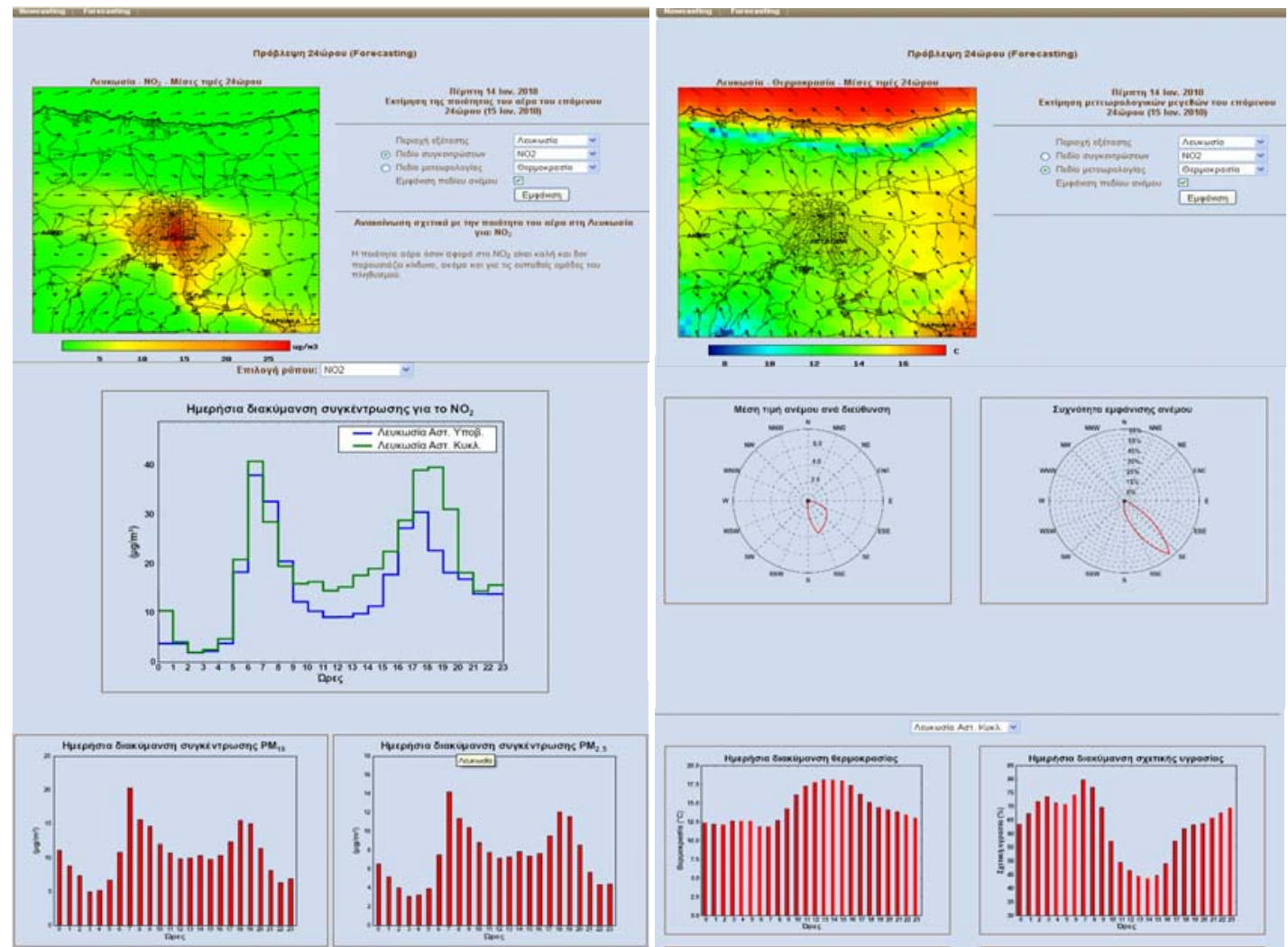

Figure 6. Snapshots of forecasting results for pollutant concentrations (left) and meteorological parameters (right) 
Furthermore, through this interface, the authorized DLI users are provided with geospatial tools for setting up emission scenarios, as well as reviewing the results of the corresponding model runs (see Figure 7).

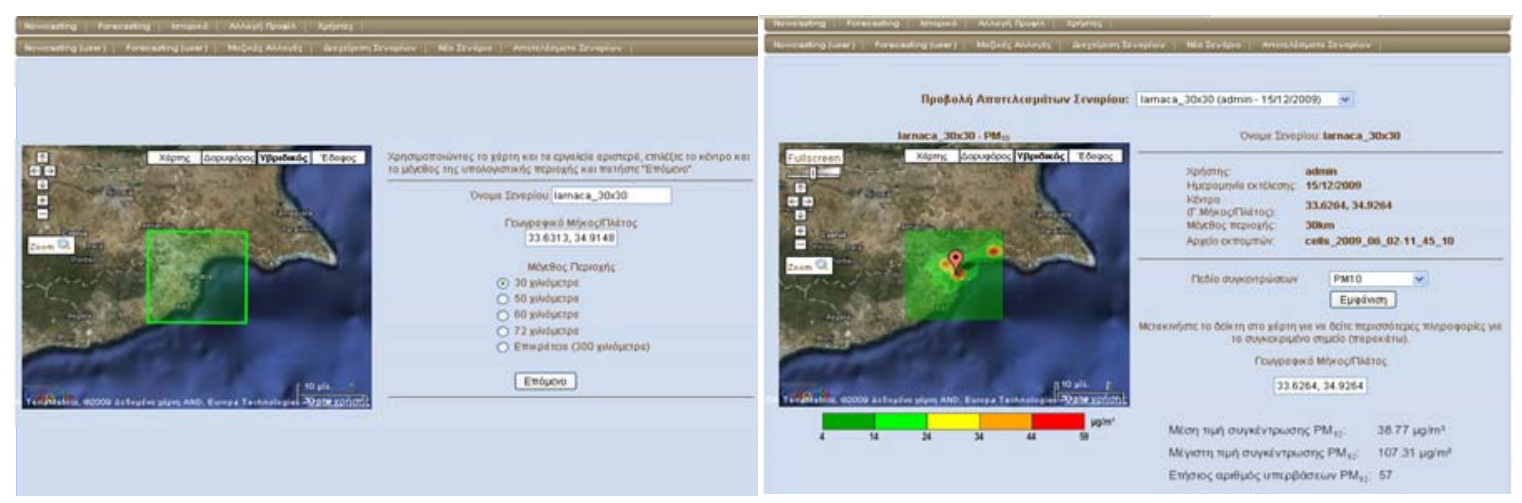

Figure 7. Emission scenario set up (left) and scenarios results (right)

In the scenarios results section, the DLI user can not only access pollutant concentration maps produced by the automatic process of the respective model runs, but also to manually produce statistical indices and timeseries graphs for any location inside the calculation domain, using a suitable interactive feature (see Figure 8).
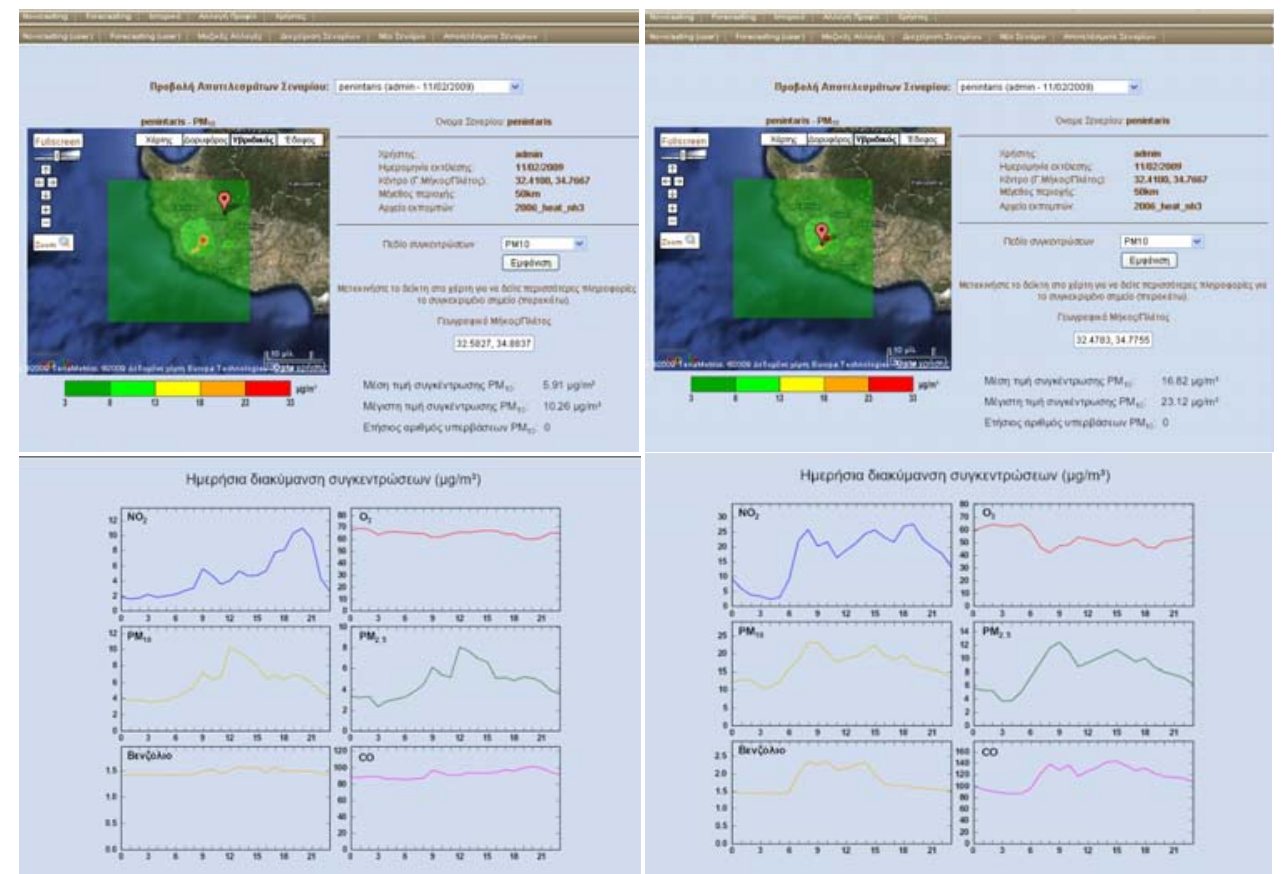

Figure 8. Statistical indices and graphs produced for two different locations inside the computational domain of a particular emission scenario

\section{CONCLUSIONS}

The AQMS developed and installed in the Department of Labour Inspection (DLI) of the Republic of Cyprus is an integrated operational state-of-the-art air quality management system for meteorological and photochemical model simulations which offers a range of features for nowcasting, forecasting and performing scenario calculations for air quality in areas of interest. Results of the calculations can be reviewed in detail by the DLI, while they can also be accessed in a condensed form by the general public via a user-friendly web page. The AQMS can also be operated by authorised DLI users to support air quality related assessment and decision making by performing air quality calculations based on custom emission scenarios. The system is currently being tested and refined to meet the needs of the 
department. The capabilities offered by this AQMS for producing high quality assessments of air quality are expected to be a valuable aid to the authorities of Cyprus towards compliance with the relevant EU standards.

\section{ACKNOWLEDGEMENTS}

This work was co-financed by the EU in the framework of the transition facility 2005 for Cyprus. We would also like to thank the director of DLI Leandros Nicolaides, the DLI team involved in the project, as well as our colleagues from the Laboratory of Applied Thermodynamics, Aristotle University, for their valuable contribution regarding the compilation of the emissions inventory for Cyprus.

\section{REFERENCES}

1. Kleanthous S., Tsegas G., Douros I. and Moussiopoulos N. (2009), An air quality management system for Cyprus, Proceedings of the 7th International Conference on Air Quality - Science and Application (Air Quality 09) (R.-M. Hu et al., eds), Istanbul, Turkey, 24-27 March, 405-408, CD-ROM edition.

2. Moussiopoulos N. (1995) The EUMAC Zooming model, a tool for local-to-regional air quality studies, Meteorol. Atmos. Phys., 57, 115-133.

3. Moussiopoulos N., Flassak Th., Berlowitz D. and Sahm P. (1993) Simulations of the wind field in Athens with the nonhydrostatic mesoscale model MEMO, Environ. Softw., 8, 29-42.

4. Moussiopoulos N., Sahm P. and Kessler Ch. (1995) Numerical simulation of photochemical smog formation in Athens, Greece - a case study, Atm. Env., 29, 3619-3632.

5. Arvanitis A., Moussiopoulos N., Kephalopoulos S. (2001) Development and testing of an aerosol module for regional/urban scales, Proceedings of the Second Conference on Air Pollution Modelling and Simulation, APMS' 01, Champs-sur-Marne, 9-12 April, 277-288.

6. Schell B., Ackermann I. J., Hass H., Binkowski F.S. and Ebel A. (2001) Modelling the formation of secondary organic aerosol within a comprehensive air quality model system, J. of Geoph. Res., 106(D22):28275-28293.

URL1: http://wwwt.emc.ncep.noaa.gov/gmb/moorthi/gam.html

URL2: http://www.airquality.dli.mlsi.gov.cy/ 